\title{
Patient Safety Attitudes, Skills, Knowledge and Barriers Related to Reporting Medical Errors by Nursing Students
}

\author{
Hamid Safarpour', Maryam Tofighi'2, Leila Malekyan ${ }^{3 *}$, Jafar Bazyar ${ }^{4}$, Saeideh Varasteh ${ }^{5}$, \\ Rahman Anvary 6
}

${ }^{1}$ Department of Health in Disasters and Emergencies, School of Health, Safety and Environment, Shahid Beheshti University of Medical Sciences, Tehran, Iran

${ }^{2}$ Accredidation and Quality Improvement Committee, Shahid Beheshti Hospital of Ardestan, Isfahan University of Medical Sciences, Isfahan, Iran

${ }^{3}$ Department of Nursing, School of Nursing and Midwifery, Bam University of Medical Sciences, Bam, Iran

${ }^{4}$ Department of Epidemiology, School of Public Health, Ilam University of Medical Sciences, Ilam, Iran

${ }^{5}$ Department of Nursing, School of Nursing and Midwifery, Zahedan University of Medical Sciences, Zahedan, Iran

${ }^{6}$ Department of Nursing, Faculty of Medical Sciences, Tarbiat Modares University, Tehran, Iran

Email: ${ }^{\star}$ l.malkyan@gmail.com

How to cite this paper: Safarpour, H., Tofighi, M., Malekyan, L., Bazyar, J., Varasteh, S. and Anvary, R. (2017) Patient Safety Attitudes, Skills, Knowledge and Barriers Related to Reporting Medical Errors by Nursing Students. International Journal of Clinical Medicine, 8, 1-11.

http://dx.doi.org/10.4236/ijcm.2017.81001

Received: November 21, 2016

Accepted: January 17, 2017

Published: January 20, 2017

Copyright (c) 2017 by authors and Scientific Research Publishing Inc. This work is licensed under the Creative Commons Attribution International License (CC BY 4.0).

http://creativecommons.org/licenses/by/4.0/ (c) $\underset{\mathrm{EY}}{ }$ Open Access

\begin{abstract}
Introduction: Health care system structure is prone to human error. Medical errors are one of the major challenges that health systems in all countries are grappling with to minimize and reduce the damage caused by them. The aim of this study was to assess the Patient Safety Attitudes, Skills, Knowledge and Barriers Related to Reporting Medical Errors by Nursing Students in Ilam, Iran. Methods: A cross-sectional mixed method was conducted to this study. Sampling was conducted by census of all students entering nursing criteria in Ilam in 2016. A number of 140 students participated in this study. The tool used in this study was created by Schnall et al. that measures knowledge, attitudes and skills related to medical errors reporting. Data were analyzed with $t$ test, regression and correlation coefficients and descriptive statistical methods. Results: The results showed that nursing students had a positive attitude with respect to the reporting of medical errors $(\mathrm{p}=0.01)$. They also have the low knowledge to medical errors and reporting them. There were significant differences in all groups and subgroups of knowledge, attitude, and skills (except creating of safety culture subgroup) between the two group's students. Moreover, the main reason for not reporting was the lack of knowledge and fear of punishment. Conclusions: The results of this study help those who involve in the health care system to improve patient safety and improve the process of reporting medical errors by nursing students' participation in the process of reporting error, while improving knowledge and attitudes through nursing
\end{abstract}


education with the effective educational models. As a result, there is a need to educate students on reporting systems.

\section{Keywords}

Medical Error, Reporting Error, Nursing Students, Barriers, Ilam

\section{Introduction}

Health care system structure is prone to human errors. Medical errors are one of the major challenges that health systems in all countries are grappling with to minimize and reduce the damage caused by them. Studies show that $3-17$ percent of patients admitted to hospitals suffer an injury or condition that occurs as a result of medical errors or adverse event [1]. According to the Institute of Medicine in 1999, approximate 44 to 98 thousand people have lost their lives as a result of medical errors [2]. In the United States, approximate 400 thousand deaths from medical errors occur annually and medical errors are the third leading cause of death in the United States [3]. Patients are entitled to safe care by health care providers. To prevent and reduce medical errors, health care system as a whole needs to change policies and procedures. Although evidence suggests that recurrence of medical errors can be prevented by the reporting system, but medical errors continue because of the lack of reporting of medical errors. Results of a study showed that 50 to 96 percent of medical errors are not reported. In addition it was shown that $96 \%$ of medical errors are not evaluated or their recurrence in the future is not prevented [4]. Many studies were conducted on the use of medical errors reporting systems and barriers associated with these systems by nurses. Barriers identified by the nurses include: the completion of error reporting time, lack of knowledge about the occurrence of error, belief in the need to report an error, providing an error as reality or denial, embarrassment or fear of punishment for error reporting [5] [6]. Various studies have linked the lack of knowledge regarding the reporting of medical errors as common barrier. According to the Department of Health and Human Services, the hospital staff does not report 86 percent of medical errors, partially due to inadequate understanding of that what damage can happen to their patients by failing to report [7]. Medical errors reporting system should take priority in accordance with health care providers training and evaluation report. Understanding and identifying reporting errors and barriers to it can help to increase the percentage of reporting medical errors. There will be strong and effective changes in the attitudes and behavior of employees, if provided with repeated and reinforced education [8]. Nursing education programs should include medical errors reporting training to introduce them repeated in and increased use of errors reporting system. Cooper in 2012 stated that introducing errors reporting system in the early years of education could reduce barriers to reporting and improve the error reporting [9]. Health care providers can be very effective to 
reduce the number of errors that occur by using error reporting system [10]. It is estimated that each year over three million preventable adverse events occur in hospitals [11]. Knowing the underlying causes of these errors is necessary to prevent a repeat occurrence of similar incidents. However, to understand the root causes of such errors, first, in most cases, the error should be repeated. The potentially harmful nature of these errors, the number of medical errors that occur in hospitals is unacceptable. Thereby reducing the incidence of medical errors must be a priority to improve patient safety [12]. The evaluation of reporting barriers in reporting systems is a fundamental step to reduce medical errors and improve patient safety. Nursing students are key beneficiaries in an effort to reduce medical errors with the ability to help to improve medical errors reporting systems. Promote clear understanding of medical errors and barriers to reporting are essential to develop effective measures to increase the use of error reporting systems. Therefore, the objective of this study is to understand the barriers to reporting medical errors by nursing students.

Hospitals and other health service providers must take action to improve the reporting of medical errors and improve quality of care through learning from mistakes. In general, the reporting of medical errors should become a culture in health care centers, and this is to boost the use of error reporting systems by reducing the fear of punishment. Many studies have examined barriers to reporting of medical errors through physician and nurses perspectives, however, few studies conducted on the barriers to reporting and perception of medical errors by nursing students. Therefore, awareness of the importance of reporting medical errors should be started during nursing education. All health care professionals, including nursing students are required to report medical errors. Balas et al. (2004) studied 393 nurses and showed that 30 percent of nurses have reported at least one error [13]. Nursing students may have much concern for various reasons to report a medical error; however, the attitude towards the reporting of medical errors could be affected through appropriate education and creating culture of reporting .Knowing the barriers to use medical error reporting systems by students can help the importance of nursing education in promoting the safety culture [14]. Yaghobi et al. (2015) results titled "The incidence of medication errors in nursing students and their views on not reporting the error among senior nursing students" using a questionnaire containing 17 statements about students' demographic characteristics and causes of not reported medication errors in the three domains of fear of the consequences of reporting, management factors and reporting factors show that among the aspects surveyed the higher score went to reporting factors, that forgetting the medication errors reporting by students accounted for most points. Given the domains of fear of the consequences of reporting medication errors by a student the fear of news dissipation in the faculty and among other students gained the higher score. Moreover, in the area of management factors higher scores went to the disproportionate instructor's reaction to the severity and importance of errors in reporting and forgetting the medication errors reporting by students. Also fear of news dissipa- 
tion in the faculty and among other students, absence of a precise definition of medication errors, fear of informed the physician and blamed by them, fear of error detection and legal problems followed, and unimportance of medication errors reporting from the perspective of students were the five main causes of not reported medication errors by students in terms of single causes of not reported medication errors by nursing students [15]. Another study (2012) was conducted to examine the causes of not reporting medical errors from the perspective of nursing managers, supervisors, and head nurses in all clinical wards of a hospital. In this study the causes of not reporting medical errors has been classified in four categories. Results show fear of punishment by direct supervisor, high workload the individual exposed to charge and considering error reporting as useless were of great importance. Also created extra work for the person (to report) and loss of reputation or job were of the utmost importance from both groups perspectives. The cost of ineffective reporting from the supervisor's perspective gained the least importance, but was of the utmost importance from head nurse perspectives. Moreover, the possibility of cancelling the employment contract was of the most importance on the view of supervisors, but with the least importance on the view of head nurses [16]. Another study examines barriers to reporting by nurses and doctors to modify the this behavior, The questionnaire used in the study also showed that barriers to reporting and lack of adequate knowledge and allowed researchers to determine the most adjustable barriers. The barriers include structure and process as well as lack of knowledge [6]. According to the authors study, specifically, the use of questionnaires is the most common method to study the reporting barriers. Healthcare Research and Quality Agency proposed two different tests to evaluate the overall safety culture in 2012: Examination of patient safety culture and safety attitudes questionnaire [17]. While these tests help to determine the perceived safety of health care, none specifically assess knowledge. Many studies have reported a lack of knowledge as a barrier in medical errors reporting [18] [19]. As a result, to add knowledge assessment, as part of future studies to examine barriers to reporting medical errors by nursing students is important. Therefore, the aforementioned study should be modified to be used in this study and knowledge assessment should be added as part of this tool. One of the developed tools that added knowledge assessment as part of the evaluation is Schnall et al. (2008) test of patient safety knowledge, skills and attitudes [20]. According to above literature, the aim of this study was to assess the Patient Safety Attitudes, Skills, Knowledge and Barriers Related to Reporting Medical Error by Nursing Students in Ilam, Iran.

\section{Methods}

A cross-sectional mixed method (quantitative and qualitative) was conducted to this study. Sampling was conducted by census of all students entering nursing criteria in Ilam in 2016. A number of 140 students participated in this study, 18 of whom were Master of Science in nursing student (MSN) and 122 were Ba- 
chelor of Science in nursing student (BSN). Inclusion criteria included: students who passed at least one course of clinical practice in a hospital environment. The exclusion criteria were dissatisfied students, freshmen without hospital and clinical backgrounds. The tool used in this study was Patient Safety attitudes, skills and knowledge scale (PS-ASK) that created by Schnall et al. (2008). This tool has been created for use in nursing programs and therefore was suitable to examine the study variables. This tool items were based on five-scale Likert including three content groups including knowledge, skills and attitude. Attitude scale consists of 9 items and was divided into three subgroups of error detection, time investment and creating a culture of safety. Literature has determined that attitude, as lack of knowledge is a common barrier to medical errors reporting [21] [22] [23]. Skills scale consists of 13 items and was divided to the subgroups of error analysis, decision support technology, and threats to patient safety. Knowledge scale consists of 4 items. However, this tool was not able to measure some barriers to reporting medical errors which could affect the nursing students such as understanding the need to report the error, fear of punishment or fear of creating a problem for the another; therefore to get more information an open-ended questions was added to the questionnaires study other barriers [19]. The open-ended question was "Is there anything that may prevent you from completing an error report after a near miss or adverse event occurs?" First, the questionnaire was translated into Farsi by two people fluent in English. Then to match it with the English questionnaire was translated into English by two linguists. Content validity test was used to check for validity. The tool was handed to 10 college experts. After examining the content validity, the index of 0.87 was reported. To pilot test, 30 questionnaires were distributed among 30 samples and after 10 days the test-retest was conducted. Cronbach's alpha coefficient was measured after data was collected using SPSS 21 software. Alpha coefficient of 0.81 was calculated in this study. All parts of the questionnaire data and qualitative open-ended question were analyzed separately. After data collection, data analysis was performed using the SPSS v.19 software. Descriptive statistics were calculated. Normality of data distribution was confirmed by KolmogorovSmirnov test. Then, data was analyzed with $t$ test, regression and correlation coefficients and descriptive statistical methods. Significance as well as $\mathrm{P} \leq 0 / 05$ was determined.

\section{Results}

The number of 140 students participated in this study, $12.9 \%(\mathrm{n}=18)$ were MSN student and $87.1 \%(\mathrm{n}=122)$ were BSN students. Table 1 shows the demographic characteristics of nursing student in this study.

The mean and standard deviation were compared based on two groups of BSN and MSN students with inclusion criteria. Table 2 shows the overall scores of attitude, skills and knowledge and associated subcategories. The results showed that students' attitudes about medical errors were higher among MSN student. Also, there was a significant difference between skill category especially 
Table 1. Demographic characteristics of nursing students.

\begin{tabular}{ccc}
\hline \multicolumn{2}{c}{ Characteristics } & Frequency (Percent) \\
\hline \multirow{2}{*}{ Sex } & Female & $82(58.6 \%)$ \\
& Male & $58(41.4 \%)$ \\
Marital Status & Single & $113(80.7 \%)$ \\
& Married & $27(19.3 \%)$ \\
Level of Education & BSN student & $122(87.1 \%)$ \\
& MSN Student & $18(12.9 \%)$ \\
\hline
\end{tabular}

Table 2. Overall Scores of Attitude, Skills and Knowledge and Associated Subcategories.

\begin{tabular}{cccc}
\hline & $\mathrm{N}$ & Mean & SD \\
\hline Attitude & 140 & 3.86 & 0.25 \\
Error Detection & 140 & 4.07 & 0.46 \\
Time Investment & 140 & 4.26 & 0.70 \\
Creating a Culture of Safety & 140 & 3.26 & 0.66 \\
Skills & 140 & 2.75 & 0.65 \\
Error Analysis & 140 & 1.9 & 0.74 \\
Decision Support Technology & 140 & 3.71 & 0.75 \\
Threats to Patient Safety & 140 & 3.30 & 0.76 \\
Knowledge & 140 & 2.96 & 0.91 \\
\hline
\end{tabular}

in the threats to patient safety subcategory in both groups $(\mathrm{p}=0.0001)$ and MSN students showed higher confidence and were able to provide and improve patient safety. Table 3 outlines the differences between the two student groups in each category and subcategory. There was no significant difference between the creating a culture of safety in both groups $(\mathrm{p}=0.43)$. Also there is statistically significant difference in the subcategory of error detection in the skills category and MSN students' attitudes were more in error detection $(\mathrm{p}=0.0001)$. In addition, results showed that there was a significant difference between the two groups in terms of knowledge and the knowledge of MSN students was more ( $\mathrm{p}$ $=0.007)$. There was a negative statistically significant relationship between the two subcategories of creating a culture of safety and error detection $(\mathrm{p}=0.034, \mathrm{r}$ $=-0.7$ ) (Figure 1). Also There was a negative coefficient correlation between the creating a culture of safety and knowledge and students whose attitudes were more toward creating a culture of safety had less knowledge about the safety of patients $(\mathrm{p}=0.003, \mathrm{r}=-0.6)$. These results show the important effects of creating a culture of safety. The highest positive response went to the error detection and the highest negative response was to creating a culture of safety. This shows that students' attitude was more toward creating a culture of safety and less toward errors detection. In addition, results showed that most students understand 
Table 3. BSN and MSN nursing students Scores of Attitude, Skills and Knowledge and Associated subcategories.

\begin{tabular}{cccc}
\hline & $\begin{array}{c}\text { Mean (SD) } \\
\text { MSN Students }\end{array}$ & $\begin{array}{c}\text { Mean (SD) } \\
\text { BSN Students }\end{array}$ & p Value \\
\hline Attitude & $3.91(0.31)$ & $3.81(0.23)$ & 0.01 \\
Error Detection & $3.94(0.46)$ & $4.27(0.41)$ & 0.0001 \\
Time Investment & $4.39(0.50)$ & $4.09(0.90)$ & 0.003 \\
Creating a Culture of Safety & $3.23(0.65)$ & $3.31(0.72)$ & 0.43 \\
$\quad$ Skills & $2.95(0.69)$ & $2.50(0.53)$ & 0.0001 \\
Error Analysis & $2.10(0.80)$ & $1.65(0.60)$ & 0.0001 \\
Decision Support Technology & $3.88(0.78)$ & $3.50(0.67)$ & 0.001 \\
Threats to Patient Safety & $3.53(0.69)$ & $3.01(0.77)$ & 0.0001 \\
Knowledge & $3.17(0.90)$ & $2.70(0.89)$ & 0.007 \\
\hline
\end{tabular}

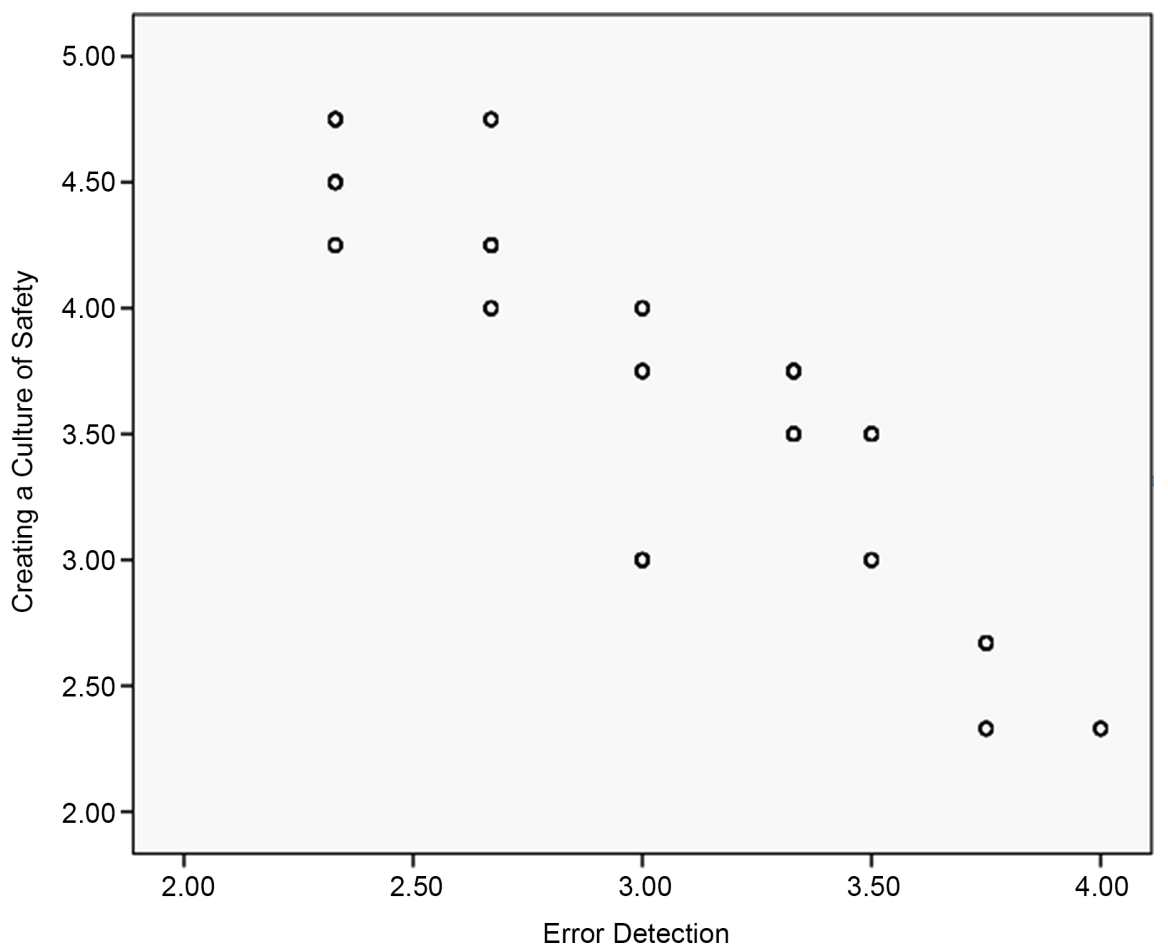

Figure 1. Correlation between creating of culture and error detection.

the importance of reporting medical errors. Some students also had negative attitudes and this could indicate that enhanced the experience and knowledge related to patient safety and reporting medical errors can lead to cynical perspective when involved in medical errors reporting. In addition, the higher score of knowledge of students on patient safety was in correlation with lower scores in the attitude towards patient safety. In other words, most of the students who had more knowledge about patient safety had fewer attitudes towards creating a culture of safety. There was a significant positive relationship between knowledge 
and error analysis subgroup, and students with more knowledge were more skillful in error analysis $(p=0.002)$. For aim to reporting error asked an openended question to nursing students. 103 of student (74\%) answered to openended question: "is there anything that may prevent you from completing an error report after a near miss or adverse event occurs?" 87 samples stated the followings: fear of punishment, reaction and pressure from staff, lack of knowledge and confidences about the occurrence of error, being out of their business, neglecting their responsibility to report an error, a lack of knowledge about how to report and notoriety among the other students and Staff. The greatest reason for not reporting was lack of knowledge and fear of punishment. Overall findings showed that students are afraid of reporting errors and lack enough knowledge.

\section{Discussion}

Patient safety must be the first priority of Health care provider. Theoretical grounds should be combined with educational experiences following the development of knowledge, skills and attitudes for effective patient safety. Evaluation of nursing students' attitude towards the reporting of medical errors is important because attitudes can affect behavior. There was no enough study about medical errors in nursing students for better comparison. Our study results indicated that the positive attitude of students toward medical errors reporting has a valuable effect on improving patient safety and in contrast creating the culture of safety showed less effect. The answer to open-ended question results showed that barriers such as fear of punishment and pressure by other staff after error reporting reflect the culture of the students in the academic environment. Reporting culture should be a norm on health care environment. Learning how the system and attitude cause errors is the first step in the development process to prevent similar errors in the future. Create a punitive culture associated with medical errors has little effect on reducing errors [24]. Safety culture, although ideal, may not be applicable in all areas. The results showed that there is a condition of uncertainty about the safety culture in health care in nursing students. Statements, such as fear of punishment and errors detection, may be followed with problems reflects the punitive culture of nursing environment. Skills gained lower scores than other aspects, and students were at lower levels of competency in the risk analysis subgroup. Nurse's knowledge on understanding of medical errors and reporting them was low. Overall findings showed that students are afraid of reporting errors and lack enough knowledge, thus requiring reporting systems trainings.

\section{Conclusion}

Improving patient safety should be the goal of all health care professionals which should start as a strong base of experience and education of professional health care specialists. The current study emphasis is on medical errors reporting and patient safety that should be included in nursing training programs. The study 
showed nurses lack of knowledge and attitude in relation to patient safety. Nursing programs may be somewhat improved the situation, but students will not acquire adequate skills and knowledge as long as nursing education is not based on a model and purposeful. Although there are processes in reports of medical errors, nursing students are not involved in this process and, therefore, students do not have enough skills to analyze the error. The study shows the need to create a culture of reporting to assist medical errors reporting in Training nurses. Creating and developing a culture of reporting could reduce students' fear of errors reporting resulting in improving the reporting process and ultimately may cause a professional positive attitude towards the reporting of medical errors. Based on the results of open-ended questions, to clarify reporting was one of the problems and a number of participants indicated that there is the lack of transparency in the reporting of medical errors in the academic environment. Transparency can help students understand the importance of errors reporting. Therefore, students must participate in the process of error analysis and be informed of the changes that occur as a result of reporting the same errors in the future. The results of this study help those who involve in the health care system to improve patient safety and improve the process of reporting medical errors by nursing students' participation in the process of reporting errors, while improving knowledge and attitudes through nursing education with the effective educational models.

\section{References}

[1] Sari, A.B., Sheldon, T.A., Cracknell, A. and Turnbull, A. (2007) Sensitivity of Routine System for Reporting Patient Safety Incidents in an NHS Hospital: Retrospective Patient Case Note Review. British Medical Journal, 334, 79. https://doi.org/10.1136/bmj.39031.507153.AE

[2] Institute of Medicine (1999) To Err Is Human: Building a Safer Health System. Retrieved September 17, 2014.

[3] James, J.T. (2013) A New, Evidence-Based Estimate of Patient Harms Associated with Hospital Care. Journal of Patient Safety, 9, 122-128. https://doi.org/10.1097/PTS.0b013e3182948a69

[4] Wu, A.W. (2011) The Value of Close Calls in Improving Patient Safety: Learning How to Avoid and Mitigate Patient Harm. Joint Commission Resources.

[5] Mayo, A.M. and Duncan, D. (2004) Nurse Perceptions of Medication Errors: What We Need to Know for Patient Safety. Journal of Nursing Care Quality, 19, 209-217. https://doi.org/10.1097/00001786-200407000-00007

[6] Uribe, C.L., Schweikhart, S.B., Pathak, D.S., Marsh, G.B. and Fraley, R.R. (2002) Perceived Barriers to Medical-Error Reporting: An Exploratory Investigation. Journal of Healthcare Management, 47, 263.

[7] Levinson, D.R. (2012) Hospital Incident Reporting Systems Do Not Capture Most Patient Harm. Office of the Inspector General, Washington DC. http://oig.hhs.gov/oei/reports/oei-06-09-00091.pdf

[8] Woodward, H.I., Mytton, O.T., Lemer, C., Yardley, I.E., Ellis, B.M., Rutter, P.D., Greaves, F.E., Noble, D.J., Kelley, E. and Wu, A.W. (2010) What Have We Learned about Interventions to Reduce Medical Errors? Annual Review of Public Health, 31, 
479-497. https://doi.org/10.1146/annurev.publhealth.012809.103544

[9] Cooper, E.E. (2012) A Spotlight on Strategies for Increasing Safety Reporting in Nursing Education. The Journal of Continuing Education in Nursing, 43, 162-168. https://doi.org/10.3928/00220124-20111201-02

[10] Koczmara, C., Dueck, C. and Jelincic, V. (2006) To Err Is Human, to Share Is Divine. Dynamics, 17, 22-25.

[11] US Department of Health and Human Services, US Department of Health and Human Services (2010) Agency for Healthcare Research and Quality. National Healthcare Quality Report.

[12] Leapfrog Group (2013) Hospital Errors Are the Third Leading Cause of Death in US and New Hospital Safety Scores Show Improvements Are Too Slow.

http://www.hospitalsafetyscore.org/newsroom/display/hospitalerrors-thirdleadingc auseofdeathinus-improvementstooslow

[13] Balas, M.C., Scott, L.D. and Rogers, A.E. (2004) The Prevalence and Nature of Errors and Near Errors Reported by Hospital Staff Nurses. Applied Nursing Research, 17, 224-230. https://doi.org/10.1016/j.apnr.2004.09.002

[14] Vaismoradi, M., Salsali, M. and Marck, P. (2011) Patient Safety: Nursing Students' Perspectives and the Role of Nursing Education to Provide Safe Care. International Nursing Review, 58, 434-442. https://doi.org/10.1111/j.1466-7657.2011.00882.x

[15] Yaghoobi, M., Navidian, A., Charkhat-Gorgich, E.A. and Salehiniya, H. (2015) Nurses' Perspectives of the Types and Causes of Medication Errors. Iran Journal of Nursing, 28, 1-10.

[16] Movahednia, S., Partovishayan, Z., Bastanitehrani, M. and Moradi, F. (2014) Nurse Managers' Perspectives about Reasons for Not Reporting Medical Errors in Firoozgar Hospital: 2012. Razi Journal of Medical Sciences, 21, 110-118.

[17] Pettker, C.M., Thung, S.F., Raab, C.A., Donohue, K.P., Copel, J.A., Lockwood, C.J. and Funai, E.F. (2011) A Comprehensive Obstetrics Patient Safety Program Improves Safety Climate and Culture. American Journal of Obstetrics and Gynecology, 204, 216.e1-216.e6. https://doi.org/10.1016/j.ajog.2010.11.004

[18] Dolansky, M.A., Druschel, K., Helba, M. and Courtney, K. (2013) Nursing Student Medication Errors: A Case Study Using Root Cause Analysis. Journal of Professional Nursing, 29, 102-108. https://doi.org/10.1016/j.profnurs.2012.12.010

[19] Espin, S. and Meikle, D. (2014) Fourth-Year Nursing Student Perceptions of Incidents and Incident Reporting. Journal of nursing Education, 53, 238-243. https://doi.org/10.3928/01484834-20140217-04

[20] Schnall, R., Stone, P., Currie, L., Desjardins, K., John, R.M. and Bakken, S. (2008) Development of a Self-Report Instrument to Measure Patient Safety Attitudes, Skills, and Knowledge. Journal of Nursing Scholarship, 40, 391-394. https://doi.org/10.1111/j.1547-5069.2008.00256.x

[21] Benbassat, J., Pilpel, D. and Schor, R. (2001) Physicians' Attitudes toward Litigation and Defensive Practice: Development of a Scale. Behavioral Medicine, 27, 52-60. https://doi.org/10.1080/08964280109595771

[22] Force, M.V., Deering, L., Hubbe, J., Andersen, M., Hagemann, B., Cooper-Hahn, M. and Peters, W. (2006) Effective Strategies to Increase Reporting of Medication Errors in Hospitals. Journal of Nursing Administration, 36, 34-41. https://doi.org/10.1097/00005110-200601000-00009

[23] Madigosky, W.S., Headrick, L.A., Nelson, K., Cox, K.R. and Anderson, T. (2006) Changing and Sustaining Medical Students' Knowledge, Skills, and Attitudes about Patient Safety and Medical Fallibility. Academic Medicine, 81, 94-101. 
https://doi.org/10.1097/00001888-200601000-00022

[24] Robson, J., de Wet, C., McKay, J. and Bowie, P. (2011) Do We Know What Foundation Year Doctors Think about Patient Safety Incident Reporting? Development of a Web Based Tool to Assess Attitude and Knowledge. Postgraduate Medical Journal, 87, 750-756. https://doi.org/10.1136/pgmj.2011.117366

Submit or recommend next manuscript to SCIRP and we will provide best service for you:

Accepting pre-submission inquiries through Email, Facebook, LinkedIn, Twitter, etc. A wide selection of journals (inclusive of 9 subjects, more than 200 journals)

Providing 24-hour high-quality service

User-friendly online submission system

Fair and swift peer-review system

Efficient typesetting and proofreading procedure

Display of the result of downloads and visits, as well as the number of cited articles Maximum dissemination of your research work

Submit your manuscript at: http://papersubmission.scirp.org/

Or contactijcm@scirp.org 